\section{Original Article}

Dr. Arup Kumar Saha

BDS, MPH

Asst. Professor

Department of Dental Public Health

City Dental College\& Hospital, Dhaka

Dr. Most. Shahana Afroge Khan

BDS

Lecturer

Marks Dental College, Dhaka

Dr. Shaik Abdullah Al Mamun MBBS, MPH (Public Health Administration) NIPSOM, Dhaka

Dr. Diti Rani Das MBBS

Rajshahi Medical College\& Hospital Rajshahi

Dr. Helal Uddin BDS, MPH

Research Assistant \& MS (Resident) Dept. of Orthodontics Bangabondhu Sheikh Mujib Medical University, Dhaka

Dr. Md. Mustafa Kamal

$\mathrm{PhD}$

Asst. Professor

Department of Nutrition \& Biochemistry NIPSOM, Mohakhali, Dhaka

Correspondence to: Dr. Arup Kumar Saha

BDS

Asst. Professor

Department of Dental Public Health

City Dental College, Dhaka

E-mail: arupcdc@yahoo.com

\title{
Factors Affecting Oral Health in Non-Commissioned Soldiers of Bangladesh Army attended the Dhaka Combined Military Hospital
}

\begin{abstract}
:
Aims: A descriptive type of cross-sectional study was conducted comprising 100 non-commissioned soldiers of Bangladesh Army attended Dhaka combined military hospital $(\mathrm{CMH})$ during January to July 2012, to find out the factors affecting their oral health.
\end{abstract}

Materials and Methods: Data were collected by structured questionnaire. Collected data were compiled, tabulated, analyzed by computer using SPSS version 16.0.

Results: Mean age of the respondents was $30.16 \pm 5.09$ (range 2041) years where about $60 \%$ were married.Most $(91 \%)$ of themcompleted secondary school certificate. Eightypercent (80\%) lived in barracks and $97 \%$ had idea about dental diseases and $3 \%$ had not.Of all, $73 \%$ respondents brushed their teeth once daily and $27 \%$, twice daily.Majority (76\%)respondents brushed their teeth at morning and the lowest $11 \%$ after breakfast and the rest $(13 \%)$ brushed their teeth at bed time.Ninety nine percent(99\%) respondents used tooth paste as cleaning materials and only $1 \%$ respondents used something else.In this study, $40.0 \%$ visited dentist once in a year, $17 \%$ twice in a year and $43 \%$ did never visit dentist without dental problem. Usually $48 \%$ visited dental chamber for gum bleeding and only $1 \%$ visited for regular dental checkups. Among the respondents, $36 \%$ visited dental chamber for pain and $15 \%$ visited dental chamber for detection of dental caries by themselves. The notable bad habits were not observed among $84.0 \%$ of the respondents. A few respondents had smoking $(6.0 \%)$, betel nut chewing $(4.0 \%)$ and snuff dipping $(3.0 \%)$ habits. Of all,63\% of the respondents had swelling of gum and $37 \%$ had no swelling of gum. Presence and absence of calculus on the gingival margin were found $47 \%$ and $53 \%$, respectively. In view of individual perspective,2DMFT had among $40.0 \%$ respondents, followed by 1DMFT, $29 \%$, 4DMFT, $12 \%, 3 \mathrm{DMFT}, 3.0 \%$ and $16 \%$ respondents had no DMFT.

Conclusions: Overall findings suggest that the factors that affect the oral health were smoking, frequency of tooth brushing, having some bat habits and visit to dentist when dental symptoms such as bleeding gums or toothache occurred. Clinical factors included bleeding and swollen gums, toothache and caries.

Key words:Oral hygiene, dental diseases, DMFT, bad habits, cleaning aids, frequency and duration of brushing.

\section{Introduction:}

Oral health includes the general condition of the mouth, mouth cavity, teeth and associated structures. ${ }^{17}$ In Bangladesh, more than 80 percent of the population has at least one or more oral and dental diseases. ${ }^{1}$ Many suffer from periodontitis, gingivitis, dental caries, pulpitis, alveolar abscess, etc. Dental cysts and carcinoma of the oral cavity are also common oral health problems in Bangladesh. The people of rural areas are comparatively much ignorant regarding their oral hygiene. ${ }^{6,7}$ They normally use neem sticks, ashes, etc. to clean their teeth in the morning. 
A good number of people in Bangladesh are habituated of chewing betel leaf and betel nut without knowing its ill-effects. It is therefore, important to know about the effects of betel leaf on human body and oro-dental system. Other ingredients such as jarda, khoer, tamakpata (tobacco leaf), etc. are also mixed with betel leaf, betelnuts and lime to make the betel leaf eating tasty. The different ingredients of betel leaf have their respective reactions; out of these, the most harmful is betel nut. Betel nut containsaricolin, tannin, alkaliod, etc. Aricolin is almost like the nicotine in cigarette. It irritates the mucous membrane of mouth and intensifies the respiration. ${ }^{15}$ Tannins in the betel nut slightly shrink the cells. ${ }^{17,20,21}$ Lime is used with betel leafthat breaks down the alkaloid in the betel nut by metabolism. The acid juice secretion from the stomach due to chewing betel leaf makes the broken alcaloid active. The etheric oil present in betel leaf makes the tongue less sensitive. As a whole, eating of betel leaf acts as somewhat stimulant. ${ }^{20}$ Those who take betel leaf for the first time may suffer from vertigo. Regular and excessive eating of betel leaf decreases the taste of the mouth. Certain reactions are found on teeth and oral health due to eating of betel leaf. Tartars are formed at teeth roots of those who take betel leaf regularly and suffer from gum troubles. The gum decays and in many cases the bone which holds tooth root in jaws gradually decays. As a result, the teeth become unsteady and there is an early loss of teeth. ${ }^{21}$ Beside these, attrition occurs in the enamel as a result of excessive chewing of betel leaf. In certain cases, the dentin is found to be exposed due to attrition of enamel. This results tingling sensation in teeth and various sorts of troubles occur. There is evidence that the habit of taking betel leaf induce cancer in the mouth. 2,10,13,20

Oral diseases have a significant impact on the oral and general health and the well-being of all people. Oral health problems have psychological, social, and economic consequences ranging from poor self-image, social isolation, and diminished work and academic capacity. ${ }^{16}$

General Objectives: To find out the factors of oral health among the non-commissioned soldiers of Bangladesh Army attended the Dhaka $\mathrm{CMH}$.

Specific Objectives: To find out the oral health status, oral hygiene status, behavioral factors and socio demographic status among them.

\section{Materials and Methods:}

Type of study: Cross-sectional type of descriptive study.

Place of study: Combined Military Hospital (CMH) at Dhaka.

Sample size: 100non-commissioned soldiers of Bangladesh Army attended the Dhaka CMH.
Sampling technique: 100 non-commissioned soldiers of Bangladesh Army attended the Dhaka CMH during the study period and who fulfilled the inclusion and exclusion criteria were included in the study. The subjects were selected purposively.

\section{Selection criteria:}

i) Inclusion criteria:Non-commissioned soldiers attendedthe Dhaka $\mathrm{CMH}$.

ii) Exclusion criteria:Soldiers who refused to enroll the criteria.

Data collection technique: The convenient technique was adopted as the data collection technique. Data was collected by face to face interview and by oral examination.

Data analysis: Pre-designed data sheet was scrutinized 100 percent to check the quality of the raw data. It was basically a process of examination to detect errors, omission and to correct those wherever possible. The hundred percent cross-checking was done after editing, which gave a good quality of data. A code plan was developed for each and every question; the variable was defined for single observation with the value and value description according to the data type. The coded sheet was rechecked for data quality checks. The results were presented in tables in mean, standard deviation (SD) and percentage. Computers reduce the risk of human error and release time for a more thorough data processing. After editing and coding, the coded data were directly entered into the computer by using SPSS version 16.0 .

\section{Results:}

Table-1: Distribution of Respondents by age. [n=100]

\begin{tabular}{lll}
\hline Age distribution (years) & Frequency( $\mathrm{n})$ & Percent $(\%)$ \\
\hline $20-25$ years & 18 & $18.0 \%$ \\
$26-31$ years & 35 & $35.0 \%$ \\
$32-37$ years & 40 & $40.0 \%$ \\
38 and above & 7 & $7.0 \%$ \\
\hline Total & 100 & 100.0 \\
\hline
\end{tabular}

Table-1 showed that the highest number (40\%) of the respondents was in the age group of 32-37years and the lowest $(7 \%)$ was in the age group of 38 years and above. Thirty five percent(35\%) respondents fell in the age group of $26-31$ years and $18 \%$ were in the age group of 20-25years. 
Table-2: Distribution of Respondents by tooth cleaning aids.

[n=100]

\begin{tabular}{lll}
\hline Cleaning aids & Frequency $(\mathrm{n})$ & Percent $(\%)$ \\
\hline \multirow{2}{*}{ Tooth brush } & 99 & 99.0 \\
Others & 1 & 1.0 \\
\hline Total & 100 & 100.0 \\
\hline
\end{tabular}

Table-2 showed that the 99\% respondents used tooth brush as cleaning tool and only $1 \%$ respondents used something else.

Table-3: Distribution of Respondents by tooth cleaning materials.

[n=100]

\begin{tabular}{lll}
\hline Cleaning Material & Frequency $(\mathbf{n})$ & Percent $(\%)$ \\
\hline \multirow{2}{*}{ Tooth Paste } & 99 & 99.0 \\
Others & 1 & 1.0 \\
\hline Total & 100 & 100.0
\end{tabular}

Table-3 showed that the $99 \%$ respondents used tooth paste as cleaning material and only $1 \%$ respondents used something else.

Figure-1: Distribution of Respondents by dental aids used to clean their interdental spaces. [ $n=100]$

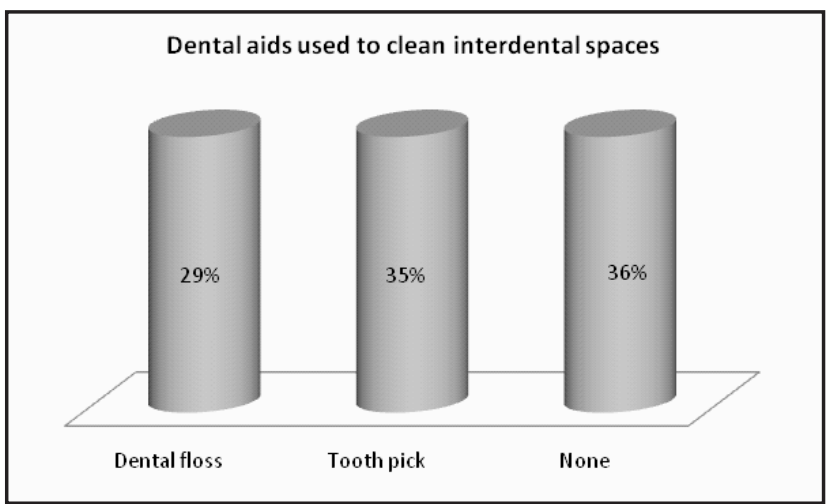

Figure-1 showed that one third of the respondents(35\%)used to clean their interdental spaces by using tooth pick, followed by dental floss $29.0 \%$ and $36 \%$ respondents did not use anything.

Table-4:Distribution of Respondents by duration and frequency of tooth brushing. [n=100]

\begin{tabular}{lll}
\hline Duration & Frequency $(\mathrm{n})$ & Percent $(\%)$ \\
\hline 1 minute & 21 & 21.0 \\
2 minutes & 25 & 25.0 \\
3 minutes & 52 & 52.0 \\
5 minutes & 2 & 2.0 \\
\hline Total & 100 & 100.0 \\
\hline
\end{tabular}

Table- 4 showed that the highest number $(52 \%)$ of the respondents brushed their teeth for 3 minutes and the lowest $(2 \%)$ respondents brushed their teeth for 5 minutes.Twenty one percent $(21 \%)$ respondents brushed their teeth for 1 minute and $25 \%$ respondents brushed their teeth for 2 minutes.

Figure-2: Distribution of Respondents by their bad habits.

$[n=100]$

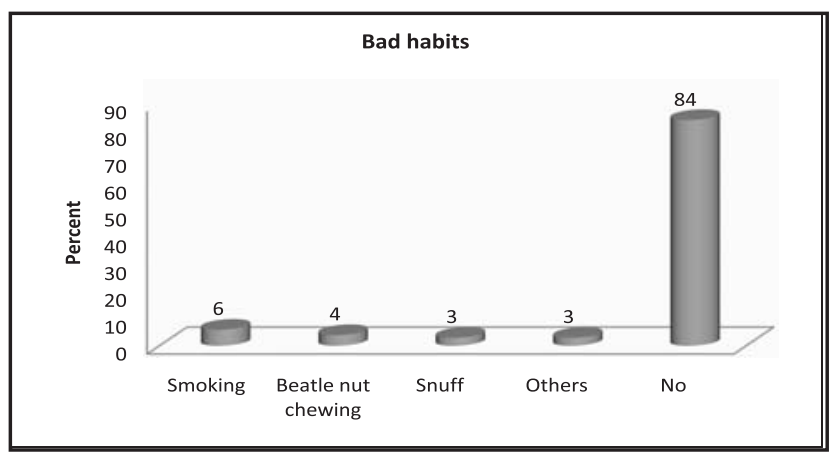

Figure-2 showed that most of the participants did not have bad habits $84.0 \%$. Respondents having smoking habits were $6.0 \%$ and betel nut and snuff dipping habits were $4.0 \%$ and $3.0 \%$, respectively.

Table-5: Distribution of Respondents by dental status (DMFT). [ $n=100]$

\begin{tabular}{lll}
\hline DMFT & Frequency $(\mathbf{n})$ & Percent $(\%)$ \\
\hline No DMFT & 16 & 16.0 \\
1 DMFT & 29 & 29.0 \\
2 DMFT & 40 & 40.0 \\
3 DMFT & 3 & 3.0 \\
4 DMFT & 12 & 12.0 \\
\hline Total & 100 & 100.0 \\
\hline
\end{tabular}

Table- 5 showed that the highest (2) DMFT had among $40(40.0 \%)$ and the lowest (3) DMFT had $3(3.0 \%)$ respondents. Twenty ninepercent (29\%)respondentshad 1DMFT and 16\%respondents had no DMFT.The rest respondents (12\%) had 4DMFT.

Table-6: Distribution of Respondentsby gingival status(colour). [ $\quad[=100]$

\begin{tabular}{lll}
\hline Colour of gingiva & Frequency $(\mathbf{n})$ & Percent (\%) \\
\hline Normal & 54 & 54.0 \\
Abnormal & 46 & 46.0 \\
\hline Total & 100 & 100.0 \\
\hline
\end{tabular}

Table showed that among the respondents, 54\% had normal gingival color and $46 \%$ had abnormal gingival color. 
Table-7: Distribution of Respondents by gingival status (bleeding gum) [ $n=100]$

\begin{tabular}{lll}
\hline Bleeding Gum & Frequency (n) & Percent (\%) \\
\hline Yes & 63 & 63.0 \\
No & 37 & 37.0 \\
\hline Total & 100 & 100.0
\end{tabular}

Table-7 showed that among the respondents, $63 \%$ had gum bleeding and $37 \%$ had no gum bleeding problem.

Table-8: Distribution of Respondents by gingival status (gum swelling). [ $\quad[=100]$

\begin{tabular}{lll}
\hline Gum Swelling & Frequency $(\mathrm{n})$ & Percent $(\%)$ \\
\hline Yes & 63 & 63.0 \\
No & 37 & 37.0 \\
\hline Total & 100 & 100.0 \\
\hline
\end{tabular}

Table-8 showed that $63 \%$ of the respondents had swelling of gum and $37 \%$ had no swelling of gum.

Table -9: Distribution of Respondents by gingival status (calculus). [ $\quad$ [ $=100]$

\begin{tabular}{lll}
\hline Calculus & Frequency $(\boldsymbol{n})$ & Percent $(\%)$ \\
\hline Yes & 47 & 47.0 \\
No & 53 & 53.0 \\
\hline Total & 100 & 100.0 \\
\hline
\end{tabular}

Table- 9 showed that among the respondents, $47 \%$ had calculus on the gingival margin and $53 \%$ had no calculus on the gingival margin.

Figure-3: Distribution of Respondents by gingival status (ulceration).

[n=100]

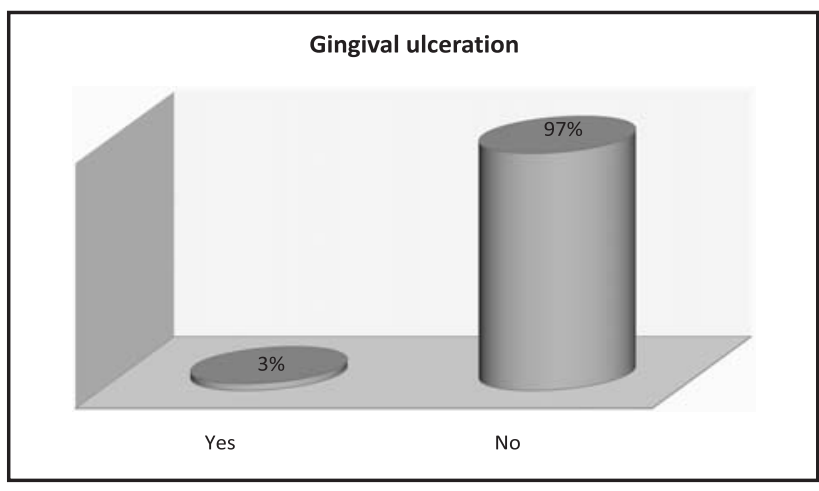

Figure-3 showed that among the respondents, 97\% had no gingival ulceration and only $3 \%$ had ulceration on gingiva.
Discussion:

Oral health is a state of being free from chronic mouth and facial pain, oral and throat cancer, oral sores, birth defects such as cleft lip and palate, periodontal (gum) disease, tooth decay and tooth loss, and other diseases and disorders that affect the oral cavity. Risk factors for oral diseases include unhealthy diet, tobacco use, harmful alcohol use, and poor oral hygiene.

Oral health is vital to human health. No part of the body works alone. Our physical structure is a complex connection that communicates and transports. The mouth although its own habitat, directly relatesto the rest of the body. It is where digestion begins, sinuses drain, and numerous bacteria form and live. Imbalances and ailments here can indicate disaccord elsewhere. And illness elsewhere can cause poor dental health. Many factors are related to oral health. The factors are mainly socio-economic factors (age, gender, source of income, housing status, etc.), behavioral factors (lip biting, nail biting, mouth breathing,etc.), disease related factors (systemic disease, on systemic disease, etc.), and so on.

The current study was carried out to find out the factors of oral health among the non-commissioned soldiers of Bangladesh Army attending the DCMH. In this study 100 cases were included the study was a cross sectional type of descriptive study.

In this study, age spectrum between 20 and 41 years, with the mean age was $30.16 \pm 5.09$ (table-1). All of the study respondents were male. About $60 \%$ were married, $36 \%$ were unmarried and $7 \%$ were in widow group. Among the respondents $45.0 \%$ were involved in farming, about $25 \%$ had family business and $30 \%$ had miscellaneous other source of income. Most of the respondents had completed secondary school certificate and that was $91.0 \%$. About $80 \%$ respondents lived in barrack followed by semipaka9.0\% and paka were $8.0 \%$. Some researchers reported socio-economic inequalities were related to oral health loss. ${ }^{15-18}$

The perceptions about dental disease of the respondents were $97.0 \%$ and only $3.0 \%$ respondent did not have idea about dental diseases. The respondents believe that improper cleaning of teeth and mouth $64.94 \%$, taking of excessive sweets $21.64 \%$ and residual food in the oro-dental cavity $13.40 \%$ are responsible for dental diseases. Bad habit like mouth breathing $8.0 \%$,tongue thrusting $1.0 \%$, lip biting $3.0 \%$, pencil biting $12.0 \%$ and Brushing $13.0 \%$ observed among the respondents. Some study revealed that Dental and oral health are affected by diet and certain aspects of lifestyle ${ }^{4-18}$. 
Among the respondents, $73 \%$ brushed their teeth once daily and $27 \%$ brushed their teeth twice daily.About $76 \%$ brushed their teeth at morning, $13 \%$ brushed their teeth at bed time and $11 \%$ brushed their teeth after breakfast. All most all of the respondents $99 \%$ cleaned their teeth by tooth brush and tooth paste.Among the respondents, $36 \%$ used nothing, $35 \%$ used toothpick and $29 \%$ used dental floss to clean their interdental spaces.Maximum respondents $(52 \%)$ brushed their teeth for 3 minutes, $25 \%$, for 2 minutes, $21 \%$, for 1 minute and only $2 \%$ brushed their teeth for 5 minutes. Respondents used their dental floss after taking food was $54 \%$ and $32 \%$ used it when needed. This Study shows that for getting brightness of teeth $38.0 \%$, due to prevent gum bleeding $28.0 \%$, to prevent dental caries $8.0 \%$ and to stop bad breathing $25.0 \%$ they did brush their teeth. Among the respondents $41 \%$ took chocolates or juice or other sweets in a day, $45 \%$ several times in a day, $38 \%$ tookirregularly and $17 \%$ respondents do not take such kinds of foods.In this study, $53 \%$ respondents used to change their old toothbrushes twice in a year and $44 \%$ changed it in every two months. $43 \%$ of the respondents did not visit their dentist without any problem, $40 \%$ visited once and $17 \%$ twice in a year.Usually they went to the dentist with complaints of gum bleeding $48.0 \%$, toothache $36.0 \%$, and caries recognizedby themwas $15.0 \%$. Negligible respondents(1\%) went for regular dental checkups. Brushing teeth infrequently and being a smoker affected tooth loss, were reported by a number of authors. ${ }^{10,12,15}$

It was the first visit in any dental hospital or for any dental treatment for $9.0 \%$ of the participants. Gilbert et al. ${ }^{11}$ found that less positive attitude to dentists, and who practiced dental hygiene less frequently and were smokers had lost more tooth. Among the respondents $10.0 \%$ had diabetes mellitus, $4.0 \%$ had hypertension and $5.0 \%$ had CVD. The notable bad habits among the study population were smoking $6.0 \%$, beetle nut chewing $4.0 \%$ and snuffing $3.0 \%$. Eklund and Burtn reported there were associations between total tooth loss and low income, education, perceived poor oral health, smoking and negative health behavior?

In this study we found single decayed tooth $54 \%$ and no decayed tooth.Among the respondents no missing tooth was in $79 \%$, single missing tooth $20 \%$ and $1 \%$ had more missing teeth.Among the respondents, no filling was in $38 \%$ respondents, single filling among $37 \%$ and $25 \%$ had more filled teeth. DMFT status of the respondents; $40 \%$ had 2 DMFT, $29 \%$ had 1 DMFT and $15 \%$ had no DMFT. Among respondents abnormal color gingival $43 \%$, gum bleeding $63 \%$, gum swelling $62.0 \%$, calculus among the gingival margin $46.0 \%$, ulceration gingival $3.0 \%$.

Dental and oral heaths are affected by diet and certain aspects of lifestyle. ${ }^{4-18}$ Data indicated that the prevalence rate of PDD, worldwide, varied from $37 \%$ to $77 \%$, depending on age of onset, oral hygiene, and other risk factors, underlying dental problems, smoking and diabetes. ${ }^{21-22}$

\section{Conclusions:}

Overall findings suggest that the factors that affect the oral health were smoking, frequency of tooth brushing, having some bat habits and visit to dentist when dental symptoms such as bleeding gums or toothache occurred. Clinical factors included bleeding and swollen gums, toothache and caries. Further broad scale studies are warranted to have an accurate conclusion.

\section{References:}

1. Beck JD, Offenbacher $S$, Williams R, Gibbs $P$, et al. Periodontitis: a risk factor for coronary heart disease. Ann Periodont Dis 1998;3(1):127-41.

2. ScannapiecoFA, Bush RB,PajuS.Periodontaldiseaseasa riskfactorforadversepregnancyoutcomes:asystematicrevi ew. Ann Periodont Dis 2003;8(1):70-78.

3. Taylor GW. Bidirectional interrelationships between diabetes and periodontal diseases: Ann epidemio Periodont Dis 2001;6(1):99-112.

4. Burt BA, Ismail AI, Morrison EC, etal.Risk factors for tooth loss over a 28-year period. J Dent Res 1990;69:1126-30.

5. Kranzler HR, Babor TF, Goldstein L, et al. Dental pathology and alcohol-related indicators in an outpatient clinic sample. Community Dent Oral Epidemiol 1990;18:204-7.

6. Locker D.Smoking and oral health in older adults. Can J Public Health 1992;83:429-32.

7. Eklund SA, Burt BA.Risk factors for total tooth loss in the United States; longitudinal analysis of national data. J Public Health Dent 1994;54:5-14.

8. Drake CW, Hunt RJ, Koch GG.Three-year tooth loss among black and white older adults in North Carolina. J Dent Res 1995;74:675-80.

9. Ylostalo P, Sakki T, Laitinen J, et al.The relation of tobacco smoking to tooth loss among young adults. Eur J Oral Sci2004;112:121-26.

10. Kressin NR, Boehmer U, Nunn ME, et al.Increased preventive practices lead to greater tooth retention. J Dent Res 2003;82:223-27.

11. Gilbert GH, Duncan RP, Crandall LA, et al. Attitudinal and behavioral characteristics of older Floridians with tooth loss. Community Dent Oral Epidemiol1993;21:384-89.

12. Slade GD, Gansky SA, Spencer AJ.Two-year incidence of toothless among South Australians aged 60+ years. Community Dent Oral Epidemiol1997;25:429-37.

13. Klein BE, Klein R, KnudtsonMD.Life-style correlates of tooth loss in an adult Midwestern population. J Public Health Dent 2004;64:145-50.

14. Copeland LB, Krall EA, Brown LJ, et al.Predictors of tooth loss in two US adult populations. J Public Health Dent 2004;64:31-37.

City Dent. Coll. J Volume-10, Number-1, January-2013 
15.Kida IA, Astrom AN, Strand GV, et al. Clinical and sociobehavioral correlates of tooth loss: a study of older adults in Tanzania. BMC Oral Health 2006;6:5.

16.Sanders AE, Slade GD, Turrell G, etal.The shape of the socioeconomic-oral health gradient: implications for theoretical explanations. Community Dent Oral Epidemiol2006;34:301-19.

17. Thomson WM, Poulton R, Kruger E, et al. Socioeconomic and behavioural risk factors for tooth loss from age 18 to 26 among participants in the Dunedin Multidisciplinary Health and Development Study. Caries Res 2000;34:361-66.

18.Stephen J. Gingivitis. Instance access to minds of medicine 2004. [Internt] [cited November 11, 2005] Available from: http://www.emedicine.com /emerg/ topic/section introduction.

19. Mallatt ME. Indiana Oral Health Survey 1992-1993 Final Report-07, 1994. [cited September 15, 2005]. Available from: www.in.gov/isdh/publications/oralhealthsurvey_94.

20.Kornman KS, Loe $\mathrm{H}$. The role of local factors in the etiology of periodontal diseases. Periodontol 1993;2:8397.

21. Genco RJ, Loe $H$. The role of systemic factors in the etiology of periodontal diseases. Periodontol 1993;2: 98116.

22. Brown LJ, Oliver RC, Loe H. Periodontal disease in USA: prevalence and role in tooth mortality. $\mathrm{J}$ Periodontol 1989;60: 363-70.

23. Kinane D, Lindhe J. Pathogenesis of periodontitis. In: Lindhe J, Karring T, Lang NP, editors. Text book of clinical periodontology and implant dentistry. 3rd ed. Copenhagen: Munksgard 1997:189-222.

24. Van der Velden U, VanVenkerhoff AJ, Abbas de Graf J. The habitat of periodontopathic microorganisms. J ClinPeriodontol 1986;13:243-8.

25. Cao CF, Aeppli DM, Liljemark WF. Comparison of plaque microflora between Chinese and Caucasian population groups. J ClinPeriodontol 1990;17:115-8. 